\title{
Fair Is Good, but What Is Fair? \\ Negotiations of Distributive Justice in an Emerging Nonmonetary Sharing Model
}

\author{
JOHANNA F. GOLLNHOFER, KATHARINA HELLWIG, AND FELICITAS MORHART
}

\begin{abstract}
By means of an ethnographic approach, this research examines perceptions of fairness and consumer behavior in an emerging nonmonetary sharing system. In contrast to market exchanges, which are defined by clear rules and principles of reciprocity, the redistribution of goods in a "sharing" context is in many cases less institutionalized and thus open to contestation. We draw on concepts from institutional theory to map out the interplay of different and partly contradicting fairness perceptions in an emerging nonmonetary sharing system and explain how those are negotiated and synthesized. We explicitly highlight a nonrelational fairness principle, leading to the stabilization of the sharing system under study through processes of "goal sharing" and "hierarchical coupling." We discuss our findings in terms of their implications on sharing theory and the role of fairness within this literature stream.
\end{abstract}

magine a table full of food-fruit, vegetables, cheese, herbs, and rice. It has been decided that this food is to be given away for free. Who should get it, and how much of it should they get? Should the recipients be those who brought it or those who need it the most? Should your friends or anyone and everyone get it?

From the example above, it is clear that fairness is not a straightforward principle but rather a multifaceted construct that strongly depends on the eye of the beholder, bringing up the question of what it means to "share fairly" in the context of resource circulation. In contrast to most market exchanges, which are defined by clear rules and principles of reciprocity, the redistribution of goods in a sharing context where monetary exchanges and straightforward reciprocal principles are absent is in many cases less institutionalized and thus can be contested.

Sharing as an alternative mode of resource circulation has only recently started to receive attention in consumer research, and thus far the question of fairness has not yet been considered in this context. This might be due to the fact that Belk's (2010) seminal conceptualization of sharing adopts a more micro-level perspective that rather focuses on dyads of donors and recipients. Recently, however, this view of sharing has been challenged by critical voices within consumer research who call for more consideration of the cultural context, including the role of norms, values, and ideologies for a holistic understanding of how resources are circulated among individuals (Siebert 2013; Arnould and Rose 2015). Similarly, research on justice in redistribution systems indicates that justice principles are relationally and socially constructed (Fehr, Bernhard, and Rockenbach 2008; Fiske 2012) and are driven by ideologies and cultural values (Feather 1994). Such social constructivist perspectives on justice indicate that in order to understand how fairness is perceived and enacted within the context of sharing, a more contextualized approach to sharing that considers the role of social and cultural influences would be needed.

Moreover, the recent boom of numerous nonmonetary consumption systems, such as Bookcrossing (Corciolani and Dalli 2014), CouchSurfing (Hellwig et al. 2014), LandShare

Johanna F. Gollnhofer (Johanna.Gollnhofer@unisg.ch), University of St. Gallen, Bahnhofstrasse 8, CH-9000 St. Gallen, Switzerland. Katharina Hellwig (Katharina.Hellwig@unil.ch), HEC Lausanne Anthropole, Unil-Dorigny CH-1015 Lausanne, Switzerland. Felicitas Morhart (Felicitas.Morhart@unil.ch), professor of marketing, HEC Lausanne Anthropole, Unil-Dorigny CH-1015 Lausanne, Switzerland. The authors would like to thank their informants for their time and their support for this project and express their gratefulness to Anton Siebert, Valeria Cavotta, and the participants of the Brand Camp IV in Obergurgl for their helpful feedback on earlier versions of this paper. Finally, the authors would like to thank the review team for their insightful and constructive comments on this article.

JACR, volume 1, number 2. Published online March 4, 2016. http://dx.doi.org/10.1086/685706

(c) 2016 Association for Consumer Research. All rights reserved. 2378-1815/2016/0102-0007\$10.00 
(McArthur 2014), or the present example of foodsharing, shows that acts of sharing are increasingly transferred from the private sphere of family and close kin to the public. Given the socially constructed nature of justice and fairness accounts, redistributive acts among strangers are likely to cause a number of tensions whenever understandings of "fair sharing" collide. An understanding of how norms of fairness are negotiated and synthesized within a particular sharing system therefore will be of importance for a more sustainable management of the plethora of sharing systems and communities that are born into the realm of the "New Sharing Economy." We therefore raise the following questions that will be addressed by the present research project: "What does it mean to "share fairly"? And how are competing perceptions of distributive justice and underlying principles of fairness negotiated and synthesized within emerging nonmonetary sharing systems?

We draw on concepts from New Institutional Theory to map out how the enactment of different principles of distributive justice reveals tensions between contesting institutional logics that strive for dominance within foodsharing - a German organization that recuperates surplus food destined to be thrown away. Explicitly, our analysis describes and explains how different principles of distributive justice are dynamically negotiated in light of competing institutional logics and how this conflict is ultimately resolved by aligning members with the initial vision of foodsharing. We discuss the role of fairness in sharing and contribute to existing research in a threefold way: (i) we show why a more contextualized view of sharing is needed to understand how fairness is constructed within a nonmonetary sharing system, (ii) we map out how redistributive conflicts embedded in competing institutional logics can be managed within an emerging sharing system, and (iii) we lay out how a superordinate institutional logic that serves to pursue a grander societal goal beyond individualistic and relational objectives could help to differentiate between sharing, gift-giving, and commodity exchange.

\section{CONCEPTUAL FRAMEWORK \\ Sharing - the Story Thus Far}

Along with a rising number of academic publications (Belk 2010, 2013; Lamberton and Rose 2012; Siebert 2013; Corciolani and Dalli 2014; Scaraboto 2015), there is a lot of attention being directed to the "New Sharing Economy" in popular media (Gansky 2010; Botsman and Rogers 2011; Sacks 2011). According to Belk (2010), the prototype of sharing is sharing within the family, in which the parents, and hence the economically and physically better equipped parties within this social group, share their resources with their children without concrete reciprocal expectations. Similarly, Benkler (2004) conceptualizes sharing as "nonreciprocal pro-social behavior." Belk (2010), whose conceptualization has strongly influenced the sharing discussion within consumer research, differentiates between sharing, gift-giving, and market exchange, following the prototypical distinctions of buying bread in a store (market exchange), the "perfect gift" (gift-giving), and unconditional sharing within the nuclear family (sharing). According to him, the major difference between sharing and other modes of good circulation is the absence of monetary payment (in contrast to market exchange) or the absence of concrete reciprocal expectations (in contrast to gift-giving). In particular, the differentiation from gift-giving has proven problematic due to the reliance on the notion of reciprocity as the major distinctive factor between both. Reciprocity in social relationships has fueled long-lasting debates within the social sciences, with critics arguing that there is no such thing as purely nonreciprocal behavior (see, e.g., Andreoni 1989; Douglas 1990; Batson 1991) and hence that sharing as per Belk's (2010) definition is nonexistent (Arnould and Rose 2015). Further confusion is fired by the misleading use of sharing in the term Sharing Economy. Many, if not the vast majority, of "sharing businesses" have nothing to do with sharing in Belk's sense but clearly represent manifestations of commodity exchange in various forms (Belk 2013; Bardhi and Eckhardt 2015). For instance, the popular peer-to-peer accommodation rental site $\mathrm{AirBnB}$ relies on principles of marketplace exchanges where users pay their hosts much like hotels. This characteristic of commodity exchange is also reflected in a myriad of academic investigations on "sharing” (e.g., Ozanne and Ballantine 2010; Lamberton and Rose 2012) that look at what has recently been better defined as "pseudo-sharing" (Belk 2013) or access-based consumption (Bardhi and Eckhardt 2015).

Although those monetary sharing systems are not in line with Belk's (2010) definition of sharing, they are nevertheless part of the public discourse on the topic that is driven by the media attention directed toward the Sharing Economy rather than by formal distinctions.

Among the nonmonetary redistributive systems associated with the "Sharing Economy," one can differentiate between gift systems that clearly rely on principles of reciprocal exchange and those systems in which such reciprocal principles are widely absent (and come closest to Belk's [2010] notion of prototypical sharing). 
In Giesler's (2006) investigation of the online consumer gift system "Napster," as well as in a cognate study on online pornography (Slater 2000), users made significant efforts to enforce reciprocal returns of other community members so that downloads of music or pornographic pictures were balanced by uploads (Slater 2000; Giesler 2006). These cases exemplify how traceable reciprocities can help to establish fairness in the nonmonetary circulation of goods. The principle enacted in the Napster study is simple: if you want to get something, you also have to give. Other studies on nonmonetary marketplaces in the Sharing Economy indicate, however, that questions of fairness are more unclear whenever such rules and norms of exchange and redistribution are blurred, hidden, implicit, or driven by diverging goals and motivations (Corciolani and Dalli 2014; Hellwig et al. 2014). Those cases, however, come closest to Belk's prototype of sharing, and hence they seem to be most interesting when it comes to investigating what fairness could mean in a public sharing context. A discussion of what fairness constitutes in the absence of graspable reciprocal claims is widely absent from discussions on sharing in consumer research, even if Belk (2010) indirectly points at the issue when discussing differing rules for the redistribution of food within the family in different cultures.

Indeed, research in cognate disciplines has shown that fairness can be seen as a fundamental human need (Bos and Miedema 2000; Akerlof and Shiller 2010) but that this need is shaped by multiple types of social and cultural factors (Feather 1994; Fiske 2012), indicating that, in order to understand what fairness means in the context of sharing, a more contextualized view on sharing might be needed.

This is in line with recent criticism of the sharing concept (Siebert 2013; Arnould and Rose 2015), arguing that a micro-level approach to sharing in consumer research, which is prominent in Belk's seminal work (2007, 2010, 2013), does not pay enough attention to cultural influences. While Belk (2010) does acknowledge and discuss differences in sharing across cultures in his work, those critics argue that the prototypical distinctions between commodity exchange, gift-giving, and sharing that are at the core of his seminal discussion of sharing are conceptual universalisms that focus too much on social-psychological processes embedded in Western culture and not enough on macro-level factors. In his study on technology-facilitated sharing among young Indonesians, Siebert (2013), for example, finds that whatever is perceived as sharing within a particular context is to a large extent socially constructed and hence depends on a variety of factors. Several studies support this line of argumentation, showing that norms and principles of good redistribution, especially in the absence of money, are influenced by the personal relationships of the involved market actors (Fiske 2012), the nature of the redistributed objects (Giesler 2006; Hellwig et al. 2014) and largely depend on the social context in the sense of norms, values, and ideologies that are prevalent in a given culture (Triandis 1994).

While work on fairness is rare in Consumer Culture Theory, the following subsection will review how existing research on justice and fairness principles in related fields can help us to understand how perceptions of fairness are negotiated within an emergent nonmonetary sharing model.

\section{What Is "Fair"? A Review of Literature on Distributive Justice}

Literature on distributive justice has long dealt with the allocation of goods, which can be seen as one of the major challenges regarding the moral implications of consumption (Wilk 2001). The question of just redistribution has been of concern to some of the most influential philosophical schools and is attributed an important role in maintaining stability in a social system such as a family, a community, an organization, or a state (Bos and Miedema 2000; Sandel 2010; Shiller 2010; Bartlett and Collins 2011).

However, fair distribution is a complex concept due to diverse interpretations and perceptions of justice and fairness. There are a number of different principles related to just distribution, but it is widely agreed upon that the most relevant are the equality, the equity, and the need principles of justice (Deutsch 1975; Forsyth 2006). According to the equality principle, all individuals are entitled to the same proportion of the shared item regardless of their contribution. The so-called equity principle holds that goods are allocated to individuals in proportion to their input. The need principle places the needs of a certain group that are deemed more disadvantaged higher than the needs of another group and thus prioritizes the former over the latter in the distribution of goods. With regard to sharing systems, an example of the equality principle can be a public library or a publicly accessible park, where all individuals have the same right to access and use the resources independently of their input (e.g., in the sense of taxes). The equity principle in turn can be mainly related to so-called pseudo-sharing models (Belk 2013) but also to gift-exchanges with clear underlying rules of reciprocity (e.g., Giesler 2006). In contrast, the need principle is reflected by prosocial institutions, such as food banks, soup kitchens, homeless shelters, or policy 
initiatives, aimed at diminishing the experienced poverty trap (Sachs 2006). To conclude, it can be said that fairness is a largely socially constructed principle. Justice judgments are not only influenced by the relationship between the involved actors but are driven by values, norms, and conventions (Feather 1994). Translated to the context of the Sharing Economy, it is therefore likely that accounts of fairness in sharing will be influenced by different conversations within the public discourse of sharing and its many facets. Sharing is not only widely considered as prosocial (Belk 2010) and environmentally friendly (Botsman and Rogers 2011) but also increasingly associated with clear capitalist ideals given that many business models of the Sharing Economy outperform traditional businesses through their efficiency, profit margins, and aggressive business practices (Cagle 2014). As distribution practices are supposed to be an enactment of underlying ideological orientations, we expect those associations with sharing to be mirrored in perceptions of fairness within our analysis of an emerging nonmonetary sharing model.

\section{New Institutional Theory as Conceptual Lens}

Recent research in consumer behavior has used New Institutional Theory (NIT) to examine and enhance the understanding of how actors interact and how markets or institutions emerge, evolve, and gain legitimacy (Humphreys 2010a, 2010b; Scaraboto and Fischer 2013; Dolbec and Fischer 2015). Given our focus on understanding distributive justice in an emergent nonmonetary sharing system, NIT provides us with the analytic tools needed to map out the interplay of different actors, logics, and justice principles that drive the distribution of resources within foodsharing (Meyer and Rowan 1977; Kraatz and Block 2008; DiMaggio and Powell 2012; Pache and Santos 2013). NIT thus helps us to answer our research questions by moving from a mostly interpersonal to a more contextualized perspective on sharing and sharing systems, which allows us to embed what we have learned from theories on justice principles in sharing research.

Businesses embedded within the Sharing Economy can be seen as hybrid or pluralistic organizations as they incorporate multiple logics (Kraatz and Block 2008; Pache and Santos 2013). Such organizations are, for instance, social enterprises that pursue a social mission (prosocial logic) based on economic activities (commercial logic). Due to their pluralistic nature, they encounter several challenges. Other than organizations incorporating one dominant logic, they have to define and prioritize an explicit goal that needs to be asserted with according institutional rules, scripts, and norms (Kraatz and Block 2008; Pache and Santos 2013).

To explain how sharing models deal with such tensions due to the influence of pluralistic logics (economic, environmental, and prosocial), we will in particular draw on the concepts of institutional logics, institutional work, and legitimization within NIT. Their usefulness to our research problem is outlined shortly in the following.

Institutional Logics. Institutions are composed of actors and entities that are "powerful carriers of institutional logics" (Pache and Santos 2013, 988). The concept of institutional logics helps to understand how particular actors act, create reality, and embody practices based on values, beliefs, conventions, and rules (Scaraboto and Fischer 2013). Thereby the concept of institutional logics is by no means totalizing, but multiple logics may coexist and result in different practices (Alford and Friedland 1985), as can be seen in the case of pluralistic organizations (Kraatz and Block 2008; Purdy and Gray 2009; Pache and Santos 2013). For instance, the pluralistic nature of sharing systems is reflected in their public perception where economic, environmental, and prosocial logics blend into each other. With sharing systems as institutions, perceptions of justice and fairness can be seen as expressions of different institutional logics. This lens helps to capture the ideological context in sharing systems that drives the enactment of justice principles, which in turn reflect underlying tensions.

Institutional Work. Competing or diverging institutional logics inform institutional work, a notion that refers to actions aimed at creating, maintaining, disrupting, or undermining rules and conventions within a given field (Lawrence and Suddaby 2006; Dolbec and Fischer 2015). As sharing systems are often relatively young, pluralistic, and emergent institutional entities, they can be particularly prone to contestation and tension between actors working to shape the institution according to their interests and beliefs. This concept will help us to analyze how several actors negotiate and strive to legitimate different institutional logics through a process of institutional work on the level of quarrels about distributive justice principles.

Balancing Different Logics. In the long term, institutional work is undertaken by organizational actors to achieve acceptance for the institution as they conceive it - within the organization as well as in the broader institutional field (Scott 2008; Purdy and Gray 2009; Humphreys 2010b). 
In the case of pluralistic organizations, this means that institutional entrepreneurs face the challenge of securing support from different internal and external actors in diverging ideological "camps." Prior research suggests three explicit strategies by means of which institutional entrepreneurs can manage diverging institutional logics (Pache and Santos 2013). The widespread strategy of "decoupling" refers to a strategy where policies are symbolically adopted although they do not match the actual organizational behavior, thus "hiding" the mismatch between logics (Crilly, Zollo, and Hansen 2012). The strategy of "compromising" strategy involves attempting to balance conflicting logics by conforming to expectations from different actors at a minimum level (Kraatz and Block 2008). "Combining" different logics, or "selective coupling," implies that competing logics might be reconciled by eclectically combining intact organizational elements and practices from different logics (Greenwood et al. 2011; Pache and Santos 2013). This threefold framework of legitimacy will help to analyze the process through which the leading actors, as institutional entrepreneurs, strive for dominance of one institutional logic while securing acceptance from internal and external actors embedded in diverging institutional logics.

\section{THE CONTEXT: FOODSHARING IN GERMANY}

Given our choice of New Institutional Theory as conceptual lens, we not only shed light on our research context of foodsharing but also consider the larger cultural and institutional context in which it is embedded. Macro-level factors that permeate from the larger economic and cultural field are expected to influence the unfolding of institutional work within the foodsharing organization and are hence presented before discussing the actual context. Foodsharing is part of the emerging Sharing Economy in Germany. Besides Sharing Economy flagships like AirBnB and Uber that have been quickly adopted, nonmonetary sharing systems like the hospitality platform CouchSurfing are particularly popular in international comparison: Germany is, for example, home to the second-largest number of CouchSurfing members worldwide (Couchsurfing Statistics 2015).

However, as an emerging population of new organizations, the Sharing Economy is an arena of conflict, especially as many business models of the new Sharing Economy are perceived as normatively and oftentimes also legally questionable from the perspective of traditional businesses (in particular with regard to tax issues, licenses, quality control, and labor legislation). The conflict can be rooted in the different logics that are pervasive in the respective na- tional economies and the industries within. Different logics, in turn, develop in response to diverting cultural influences such as history, politics, and religion, which we will outline in the following for the German context of foodsharing.

Historically, the German nation is coined by two major logics: the logic of merit and the logic of prosociality. Western Germany has been and still is one of the prime examples of industrialization and capitalism. The German economy is therefore marked by a stark commercial and meritocratic logic. At the same time, the German state is influenced by a strong social orientation - it is, for example, the pioneer of social insurance (Esping-Andersen 1989), and it has a pronounced social lobby in terms of strong labor unions and influential socialist political parties. The interplay of both logics is well exemplified by the history of the German social welfare state. Even if Germany has a long history of providing social insurance, benefits depend almost entirely on one's prior contribution and thus on work and employment. In contrast to more socialist welfare states like Sweden and Denmark, the German welfare system has a tradition of status-dependent, privileged welfare provisions that are in line with a strongly meritocratic justice ideal (Esping-Andersen 1989).

In addition, Germans have a reputation for their thrifty and disciplined lifestyle that can be explained by their history of two World Wars and the subsequent joint national efforts of reconstructing the nation and bringing it back to a livable state. Those characteristics are closely related to virtues that have become core to the recent discourse about sustainability and hence have become embedded in a logic of pro-environmentalism. Modesty and discipline in consumption and an acceptance of delayed gratification were necessary traits for avoiding starvation in post-World War Germany. Nowadays they are common elements of an anticonsumerist discourse aimed at preserving natural resources for future generations. Indeed, Germany is a strong advocate of alternative frameworks to reduce resourcedepleting practices internationally (demonstrated, e.g., by Chancellor Merkel's recent pressure for an agreement on climate goals during the G7 summit in June 2015 (Leaders' Declaration G7 Summit 2015) and by Germany's leading role in the international nuclear phase out).

These historical and political influences provide the broader sociocultural environment within which the German Sharing Economy and our concrete foodsharing research context are embedded. They influence how the underlying logics of merit, prosociality, and proenvironmentalism affect the institutional work within the foodsharing organization. 
Foodsharing.de is an online platform with the goal of saving surplus food from being thrown away and of sharing it with others. It was initiated in Germany in 2012 as a reaction to the growing awareness of living in a "throwaway society" in which large shares of produced foods end up in trashcans. Since the website's launch in December 2012, $1,996,852$ kilograms of food have been recuperated by 8,781 participating individuals, with over 63,000 people following foodsharing on Facebook and 1,902 cooperative arrangements with established retailers (as of July 8, 2015).

Initially conceptualized as a platform to facilitate the sharing of food among private persons and households, the platform nowadays mainly focuses on connecting retailers who have surplus food to give away with individuals volunteering to collect and distribute the food for further use. The role of the retailers in foodsharing is particularly noteworthy as they give away food for free although this could potentially cannibalize part of their source of revenue. No monetary flows are involved at any moment in time, and the foodsharing platform positions itself as "ethical sharing" (http://www.foodsharing.de).

Typically the collected food is redistributed at so-called Fairteilers (German for "place of fair distribution"). A Fairteiler is a publicly accessible place where the food is redistributed among participating individuals. As a gathering place for foodsharers, foodsavers, and foodsharing ambassadors, it is the place where most of the fairness judgments are enacted. The notion of "foodsharers" thereby refers to those individuals who only pick up food for their own use. "Foodsavers" in contrast are more embedded in the redistributive action, as they collect and pick up the surplus food from retailers and deliver it to the Fairteiler for further redistribution. "Ambassadors" are those individuals who are highly engaged in foodsharing and are in charge of a certain regional section. Foodsharing has developed a rather strict hierarchical structure that is geographically organized. At the top, there is a national organizers' team, followed by city heads who supervise ambassadors responsible for local sections comprising certain neighborhoods. These in turn are in charge of the foodsavers and Fairteilers in their area.

Offering a range of different economic benefits (free food), ecological benefits (reducing food waste), and benefits from prosocial behavior (feeling better), foodsharing attracts a wide range of people with different values, motivations, and convictions, which gives rise to intraorganizational tensions over the issue of who gets what and for what reason. At the same time, foodsharing is still in a state of emergence, which means that norms and rules of organizational practice are only in the formation stage.

Due to the inherent conflict potential, the emergent character of this sharing context, and the absence of concrete reciprocities in the distribution of food items, foodsharing offers a well-suited context to investigate the interplay of different justice principles within a nonmonetary sharing system.

\section{METHODOLOGY AND DATA ANALYSIS}

The present manuscript is based on a multisited collection of qualitative data. Data were collected from January 2013 until July 2015 and included participant observation, indepth interviews, and the analysis of online content, such as member profiles, blog entries, forum discussions, WhatsApp messaging groups, and news articles. The member profiles, blog entries, and forum discussions were retrieved from the official foodsharing website. Within the context of this large amount of online data, we focused our analysis on those data that seemed most pertinent to the discourse about distributive justice (in total 49 single-spaced written pages of text). Furthermore, we gathered news articles published in German newspapers directly reporting on foodsharing (43 articles).

Our data set also comprises 13 interviews with members of the local foodsharing section within which the study was conducted (appendix, available online). All interviews were conducted face-to-face by the first author. All of the interviews were conducted, transcribed, and analyzed in German-chosen quotes were translated into English. The interview guideline started with so-called grand-tour questions to elicit the general background of the informants and slowly familiarize them with the interview situation (McCracken 1988); it was designed to find out about participants' motivations, perceptions, and engagement within the field of foodsharing. Interviews lasted from 32 to 96 minutes and were captured on digital audio files and transcribed verbatim. In addition to the interview data, the first author, who is an active member of the foodsharing section under study, participated in face-to-face meetings, online, and in mobile-phone interactions. She was also part of teams that picked up food at participating supermarkets and food suppliers, and she joined several acts of redistribution in the course of this research. Total fieldnotes and introspection resulted in 47 single-spaced typed pages.

Data interpretation followed a hermeneutic approach (Thompson 1997). All three authors repeatedly read, coded, and compared the data set. The findings that are described 
in the following section emerged in an iterative process, in which the authors traveled back and forth between data and a review of relevant literature on sharing, justice principles, and institutional theory.

\section{FINDINGS}

Given the theoretical lens we adopted, our attention focused in particular on institutional work and the management of different organizational actors promoting diverging institutional logics. We identified the following main actors in the foodsharing organization. First are the foodsharing spearheads who are embedded in the proenvironmental logic. They act as missionaries to spread the idea of foodsaving and foodsharing as a form of anticonsumption to increase respectful treatment of resources. They actively engage in building and maintaining the foodsharing organization, its administration, and member recruitment. Second is a group of members who engage in foodsaving and food distribution to help economically disadvantaged people, thus promoting a logic of prosociality. Third is a group of members who engage in foodsharing mostly to save money. The last group of actors comprises the cooperating retailers. These are not members of the organization per se; however, they play a salient role as they provide the food for further distribution and confront the organization with a commercial logic of merit. They will therefore be peripherally included in the analysis.

The presentation of our results is structured into three parts. In the first part, we present the beginnings of foodsharing and its founders' basic idea before it became the setting for the kind of institutional work this article focuses on. In the second part, we lay out the tensions that arose between different actors with regard to distributive justice principles, revealing the underlying conflict between two institutional logics: a merit logic (thesis) versus a prosocial logic (antithesis). In the third part, we show how the foodsharing organizers strived to resolve this conflict by (i) introducing a third principle of distributive justice rooted in the institutional logic of proenvironmentalism as synthesis and (ii) enforcing this intended institutional logic as dominant while selectively attending to the other two contesting logics.

\section{The Original Idea of Foodsharing}

The initial vision of foodsharing was based on an idea of two German food activists who launched the fight against food waste in developed countries. Their objective was to (re)use and distribute food items that had been declared as waste by the official market. On its website (Foodsharing 2015), the official mission is declared as "instilling a new culture of respect towards food in order to give it the appreciation that it deserves. . . We want to raise awareness for the social and ecological responsibility that food companies, but also consumers, have for food waste" (official statement on the Foodsharing website, subsection "Selfconception").

From the beginning, the ultimate aim of the initiators was to educate the public with regard to the disrespectful use and depletion of human and natural resources through overproduction and overconsumption in the industrialized world. This mission manifests the organization's basic ideological anchoring in proenvironmental values and norms and strikes a chord with a range of like-minded, that is ethically-minded, foodsavers who despise what they see as the downfall of morality in today's consumption and are dedicated to acting for a respectful treatment of the social and natural environment. Such convinced foodsharing members often get emotional when talking about their observations of flawless food being thrown away in supermarkets.

Well, I felt, that hurt me. This is produced industrially, but the grain, that has grown, that has once "lived." ... But the meat has also once lived. It was killed in order to throw it away. That is so ... I don't treat humans like this, I don't treat animals like this, I am someone who treats everything with respect. (Ruby, foodsharer, interview)

Ruby reflects on the issue of food waste in moral terms, referring to the act of killing life without purpose and claiming irresponsibility and abuse of those who do not care. To those foodsavers, no plant and no animal should have lived in vain, and no worker should have invested time and energy in a product that ends up in the bin. According to this rationale, food has an immaterial, even spiritual, value that cannot be expressed in financial terms. Some informants described instances where some foodsavers, before actually sharing the food, arranged it just as on an altar and demanded a minute of devotion, which some newcomers found extreme - such as respondent Luisa, who found this practice "scientology-like" (Luisa, foodsaver, interview). As such, it is an important objective for this group of actors to educate society about the "true value" of food while indirectly criticizing the prevailing capitalist system in which the value of an item is merely measured by its market price. 
In many interviews, we found indicators that such considerations translate into missionary, if not activist, engagement. When asked about his motivation for participating in foodsharing, one member reveals:

Well, actually, I am an environmental activist. And in this way, I think, I can do a lot to protect the environment because everything that somehow gets produced is harmful to the environment. And we currently produce just too much. . . . I quickly realized that I can achieve a lot through foodsharing. I reach so many people. (Michael, foodsharing ambassador, interview)

As this comment indicates, Michael is on a bigger mission toward mobilizing others to join the "movement," as he puts it. But the enactment of this idea turned out to be not as straightforward as the organizers might have thought because the foodsharing model is dependent on and attracts different actors who pursue different interests, values, and beliefs. After a while, the foodsharing organizers were confronted with different actors championing divergent logics, leading these actors to interpret the idea of foodsharing in their own ways and enacting it through idiosyncratic rules, norms, and practices of fair game.

\section{Tensions between Conflicting Distributive Justice Principles}

This heterogeneity of motivations and interests was manifested in a series of tensions that exemplify the ongoing conflicts of competing institutional logics. To emphasize the discursive nature of these tensions, our findings are structured in the format of two positions that reproduce the format of thesis and antithesis.

"You Get What You Give." Foodsharing cannot operate in isolation from the commercial world. Instead, it is dependent on the cooperation between consumers and commercial retailers because foodsavers rely on retailers to provide them with surplus food that is going to be redistributed among private individuals. Convincing retailers was a delicate issue because giving something away for free is not in line with the modus operandi in the commercial world they are embedded in. Even retailers who in general supported the proenvironmental logic behind foodsharing were reluctant to openly display their cooperation with the organization for concerns of justice: some retailers suspected per- sonal gain by foodsavers - putting those consumers who pay the full price for the food at a disadvantage. One informant recalls a situation in a fresh produce market where a grocer blamed her for her food-saving activity:

A lady once told me... she was not sympathetic at all. Ehm ... "You should rather work more nowadays," and also, we young people, why do we do this, we are all able to work. (Alice, foodsaver, interview)

Inherent to this statement is the grocer's general displeasure about today's young people and their (allegedly nonexistent) work ethic. As a small-scale merchant, the lady belongs to a traditional profession representing the commercial business logic in its purest sense. Seeing young and employable people coming to her stand shortly before closing time to ask for unsellable leftovers for free is incompatible with her self-image as an eager and disciplined individual working hard for her income. For her, people like Alice just do not deserve to get the food for free even if it would end up in the bin otherwise because in her eyes they do not work for it. Following her logic, if they worked, they could pay for the food. For many foodsavers, criticisms like this trigger a delicate point. Indeed, there are a considerable number of members who mainly engage in foodsharing to save money, such as Luisa, who has children and does not earn a lot of money from nursing. She is sensitive to being stigmatized as a beggar or a scrounger.

In the beginning, I had a very bad conscience when there were piles of food and I carried bags [full of food] away, I thought ... yeah that's really incredible, what is this? [I] had an awfully bad conscience. . . . I felt like a hoarder, like somebody who always . . . like... stuffs her pockets. (Luisa, foodsaver, interview)

Through this confession Luisa reveals that she fully embraces the "You get what you give" narrative, which is deeply ingrained in the meritocratic society she grew up in-and which is all-present in the commercial sector. In general, she agrees with the logic of merit in the sense that she should earn her right to receive something. She only began feeling more comfortable with the situation when she started to consecrate time to cleaning up the fridge in the Fairteiler and helping whenever a new load of food arrived. Likewise, Alice acknowledges the merit logic put forth by the grocer who blames foodsavers for not working, but she gives it a different twist: 
And this [foodsaving] is also costly of course, it's not just like they [the retailers] make us rich, but it costs a lot of time for foodsavers. . . The trips to the locations cost time, also approaching retailers, this takes a lot of time. And I think this should be valued, too. . . . All foodsavers also do that for free and, ehm, of course I could say, I could do a minijob instead or something else during the time that I run around, but I don't do it. (Alice, foodsaver, interview)

Alice counters the grocer's argument by using the same "You get what you give" narrative but reinterpreting the time spent for foodsaving as a scarce and precious resource (and not an idle capacity) that she sacrifices for the food instead of a paid job, which should entitle her to receive the food. Several informants mentioned that they also paid attention to their attire and style so as not to evoke the image of being a "failed person" that is fed by the working society. Stefanie, an ambassador, tries to have her hair well done and puts on a blazer whenever she speaks to a retailer. She does not want to look "scruffy" because "it should not create the impression that I do this because I want to have food for free."

Those foodsavers that employ the "You get what you give" narrative think and act according to an institutional logic of merit, going hand in hand with an idiosyncratic understanding of distributive justice in foodsharing. According to this logic, a fair distribution of the food would be based on the principle of equity according to which goods are distributed to individuals in proportion to their input. That means that individuals who invest more of their personal time and effort in foodsharing should receive more than those that invest less. Evidently, this principle of distributive justice does not meet the needs of all members or the people interested in foodsharing and consequently clashes or contradicts with other people's expectations and behaviors. Thus, it was not long after the idea of foodsharing had gained momentum among a diverse spectrum of people that the conflict on distributive justice materialized in the organization and the question of how the saved food could be shared "fairly" was raised. Some informants referred to episodes in the Fairteilers where conflicts arose more or less openly out of breaches of the equity principle. For example, in some instances people were jealous and angry about "gypsy" children who took big amounts of food without contributing anything (Fieldnotes, collected at a Fairteiler in April 2014). One informant remembered a young woman who had brought in big amounts of food and felt "bereft" of her food, exploited, and her efforts disregarded, when her car was rushed by greedy people starting fights over the food before the woman had even fully unloaded her car. Others talked about complaints by foodsavers who had not received a fair share of food for themselves because nobody else had brought something to the Fairteiler and who thus stopped delivering. As a consequence, some Fairteilers switched to a model of centrally organized and moderated distribution, where those foodsavers who had provided something oftentimes obtained preferred treatment to honor their contribution, for example, by putting special items aside or letting them choose items first. In this way, foodsavers who represent the principle of equity try to institutionalize the logic of merit by publicly honoring engaged foodsavers. Ambassador Stefanie, who regularly moderated food distribution in one of the Fairteilers, explains:

And there comes a person who brings three boxes full of fruit and veggies. She comes, "Here you go, but I don't have time," and she does not have bread or so [but needs some]. Of course, in this case, I would favor this person in the sense of "Hey, that's really nice that you brought that stuff" [and let this person take the bread]. . . . But I always tell the group, I say "Hey, you see this person just brought this. Is it ok for you?" and then the group normally says "yes." Well, it is probably a form of favoritism, but [pause] at least one that takes place in public and not in private. (Stefanie, ambassador, interview)

In the same vein, Stefanie also enforces the logic of merit by exposing some members' little contribution and judging their taken-for-granted attitude of receiving food for free as inappropriate. Referring to the situation when there is no food delivered to the Fairteiler, either because supermarkets have no leftovers or because nobody has collected it, she explains:

Ehm, well for me it is totally ok when there is nothing, because it is not a free shop, so to say. And I do think that there are some who are not amused when there is nothing, but when they also express their displeasure, I also say "You know, that's how it is, there is as much as the group brings in. You are cordially invited. You can sign up, too." (Stefanie, ambassador, interview) 
According to Stefanie's logic of equity, there is literally no free lunch. But no official rule in foodsharing codifies such balance between giving and taking. In fact, the original idea of foodsharing was that everyone should be allowed to take the food as long as it is saved from the bin. However, the official rules did not specify any system of distribution. As situations of food distribution turned out to be unstructured and undefined, Stefanie and other supporters of the merit logic started to enforce and enact their own idea of foodsharing as a shop for those who pay with their personal engagement. However, there were other foodsharing participants that contested and undermined this reasoning by enforcing a different logic.

"Taking from the Rich to Give to the Poor." The merit logic as promoted by the "You get what you give" narrative encountered resistance from within the foodsharing organization. A group of socially concerned members questioned the meritocratic practices of those foodsavers who claimed special rights (due to their personal engagement) compared to others in the organization. This alternative group was spearheaded by one ambassador who enacted a different logic in the region that she supervised. She promulgated her own vision of foodsharing as helping the needy by distributing the saved food to asylums, homeless people, and other socially disadvantaged groups and by cooperating with charities and food banks. Cognizant of the fact that her idiosyncratic interpretation of the foodsharing mission was not in line with the institutional logic of merit that was widely prominent at that time, she strived for legitimization through a heroic "Robin Hood" narrative. She presented herself as an advocate for the poor dismantling an allegedly hypocritical system where egoism and favoritism reign. In a flaming letter posted on the official foodsharing forum, the ambassador wrote:

Who considers himself too good for distributing food to homeless people, who only wants to take and not to give (sharing!!!), should . . . not present himself as a selfless helper. (Tania, former foodsharing ambassador, online forum)

In this comment, Tania implicitly criticizes the merit logic and with it the equity principle supported by those foodsavers who claim the food they saved as theirs or who feel at least entitled to satisfy their own and their friends' needs first. She takes the wind out of those foodsavers' merit argument by steering her reasoning away from their effort to collect the food toward the benefit of obtaining ownerless food, which in theory belongs to everyone. By morally discounting the merit logic as unfair, she tries to undermine its legitimacy and impose an alternative logic of prosociality together with an idiosyncratic understanding of distributive justice. In this institutional logic, fair distribution of the food is based on the principle of need, according to which resources are allocated to individuals in proportion to their needs. In other words, the poor should get more than the rich. Indeed, this logic, packaged in a Robin Hood-like narrative, was perceived as noble by a number of foodsavers and raised a heated debate about the mission of foodsharing and the notion of fairness, which temporarily but seriously destabilized the organization. The debate escalated into a heavy fight, including personal insults, which led the ambassador overseeing the whole city to ban the ambassador who had initiated the original debate. This ban was the last resort for the foodsharing organizers. But this episode unearthed once more that they had not thought through every aspect of foodsharing and that there were still issues that needed to be negotiated.

Foodsharing is still in a process of development, it is part of the game that you can't settle yourself down in a plushy nest, that you need to grapple with and discuss things that are self-evident for yourself [but not for others]. (Kevin, foodsaver, interview)

At this point, the foodsharing organization was in the middle of a process of institutional work where two opposing groups strived to impose "their" institutional logic while undermining the contending logic in a normative dispute. The two logics were encoded in two moral narratives that were pitched against each other in a dialectical format of thesis and antithesis and were enacted by opposing practices of distributive justice. Therefore, the notion of fair sharing was subject to interpretation, contestation, and negotiation in the light of different institutional logics. The first conclusion from this research in the context of an emerging nonmonetary sharing system is that the notion of fair sharing is not a social fact but must be interpreted in light of the institutional logic it is embedded in.

Apart from this finding, it seems worth mentioning that some foodsharing members withdrew from such normative discourse by employing a more pragmatic principle of redistribution in the sense of "if everybody cares about herself, everybody is taken care of." For instance, our informant Roxane-a kindergarten teacher with regular income- 
uses foodsharing as a food-provisioning tool for her own benefit without contributing anything in return. However, members like Roxane try to sail under the radar of community attention as their practices might be qualified as freeriding. Sharing systems like foodsharing should be able to incorporate a certain number of such "freeriders" (Andrade et al. 2004) before they fall apart. However, this should only work as long as such behavior-rooted in a logic of egoism and self-interest-does not become the dominant logic. As none of its proponents strives for its dominance, it is not part of our further discussion of conflicting institutional logics.

The next subsection focuses on how the organizers of foodsharing enforced and established a common understanding of distributional justice to resolve the existing internal conflict and gain acceptance from both ideological camps.

\section{Conflict Resolution}

The disruptive forum debate about fair distribution in foodsharing unearthed a conflict on the level of institutional logics that the organizational leaders had to resolve to secure future acceptance and support from their various stakeholders. They did so by means of two strategies. The first strategy aimed to resolve the distributional conflict by introducing a third principle of distributional justice and embedding it in a synthesizing institutional logic. The second strategy aimed to enforce this institutional logic and gain acceptance for it through a purposeful mix of practices originating from the diverse logics. We will elaborate these two strategies in the next two subsections.

"Ghandi Story." Eventually, to resolve the disagreement, the organizers of foodsharing resorted to a strategy of synthesis of the contending thesis (logic of merit) and antithesis (logic of prosociality) by invalidating their inherent assumptions. Both of these institutional logics miss the central original idea of foodsharing because they resort to the micro level of individual preoccupations (an individual's effort, an individual's needs) and not to the macro-level problem of wasted natural resources that foodsharing was originally founded upon. When reminded of the initial purpose of foodsharing, Alice acknowledges that "for them it is actually, um, it is really more about the principle of saving food and not about who gets what" (Alice, foodsaver, interview).

Even more, both logics put forth by the contending parties not only miss, but even run counter to, the goal of reducing food waste. Both fuel a consumerist lifestyle by focusing attention on receiving food often in large quantities.
And both implicitly require retailers to keep supplying surplus food for foodsavers who want to economize or for the needy who might become dependent on this source of supply. As a consequence, the organizers added the following explanation to their website:

People in need may certainly cover some of their needs regarding food items through foodsharing; however there is no security of supply. The long-term objective of foodsharing is to avoid food waste and to reduce it on an on-going basis. Therefore it is of utmost importance to us that an individual may live a more self-determined life through foodsharing and nobody becomes dependent on foodsharing out of necessity. (Official statement on the Foodsharing website, section "Foodsharing and Neediness")

Although the organizers now do acknowledge that the food that is going to be saved and redistributed via foodsharing might indeed support people's subsistence needs, they clearly emphasize that this aspect is at best a beneficial side effect of a higher logic that transcends individual interests articulated in an individualistic logic of merit or personal need.

The original proenvironmental logic championed by foodsharing went astray through a conflict that materialized on the level of distributional practices. The dispute around fairness revealed a blind spot because concrete rules of distribution had never previously been defined and had left space for interpretation and contestation. To shift the focus back to the original logic of foodsharing and move the organization to the next level of institutionalization, the organizers had to fix this blind spot first. They did so by introducing a third principle of distributive justice (the principle of equality), which superseded the disagreement between the principle of equity and the principle of need. This new principle of fairness served as a "Trojan horse" for the organizers to reposition their original institutional logic of proenvironmentalism as a synthesis of the disagreement between an institutional logic of merit and an institutional logic of prosociality.

In order to appropriately enter the ongoing normative discourse, the organizers encoded their logic in a narrative that was at least as heroic as the "Robin Hood" narrative and at least as self-sacrificing as the "You get what you give" narrative. They came up with a narrative similar to an environmental "Gandhi Story." According to this narrative, foodsavers are akin to noble leaders peacefully fighting for a better world through personal example and sacrifice. They 
set an example by sacrificing parts of their valuable time and convenient lifestyle, "saving" and eating surplus "waste" food, and educating society about the perils of an overconsumerist lifestyle. On the website, the organizers nowadays even refer to Gandhi:

To become pioneers in the battle against the mindless waste and to jointly write history in order to follow Gandhi and live the change we want to see in this world. (Official statement on the Foodsharing website, section "Self-conception")

Through the Gandhi narrative, the foodsharing organizers raise the discourse to a higher level than the previous narratives. The Gandhi narrative takes the wind out of foodsharers' previous debate by steering the reasoning away from "small-minded" interpersonal occupations with the question of who gets what toward a big common goal beyond individual interests. By framing their endeavor as an epic joint battle for future generations, the foodsharing organizers morally elevate the object (reduction of foodwaste) over the subject, respectively the common goal over individual interests. As such, they introduce a third principle of fairness, which goes beyond the principles of equity and need: the principle of equality. According to this principle, the fairest allocation is one that distributes benefits and burdens equally among all parties. Put in the words of the foodsharing organizers' mission, that means that in order to ensure that all future generations can benefit from natural resources as do current generations, all human beings have to contribute in a joint effort to treat these resources respectfully and preserve them. Through this principle of equality, foodsharing organizers provide a synthesis of the dialectical struggle between equity and the need principle. With it comes a resolution of the dialectical struggle on the level of institutional logics, as the equality principle offers the logic of proenvironmentalism as a synthesis over the struggle between the logic of merit and the logic of prosociality. We visualize the evolvement of the discourse described in this subsection in figure 1. By promoting proenvironmentalism as the dominant logic, the foodsharing organizers acted as institutional entrepreneurs by defining a clear identity (Gandhi-inspired environmentalists) and singular goal (saving discarded food) for the organization.

Managing Diverse Logics. Although the organizers offered a synthesis to overcome the internal conflict between the logic of merit and that of prosociality, they nevertheless faced the challenge of securing adherence and support for the dominance of the proenvironmentalist logic (and the related equality principle as the norm of redistribution). In the following, we present the organizers' actions of managing this conflict by means of the literature on organizational responses to competing institutional logics (Kraatz and Block 2008; Pache and Santos 2013). Concretely, in their function as institutional entrepreneurs, the organizers engaged in a strategy of "selective coupling" (Pache and Santos 2013), as they enacted a combination of activities and practices drawn from each of the three logics to secure the general endorsement of diverse internal and external actors originating from different ideological "camps." However, the selective coupling of elements was guided by, and in favor of, an organizational identity and unified goal the organizers still had to enforce in the first place. Consequently, they resorted to a strategy that we will call "hierarchical coupling" in order to support the dominance of the intended proenvironmentalist logic while tolerating divergent logics on a selective and instrumental basis.

First, to promote the proenvironmental logic, the organizers actively engaged in educational and cultural activities to enforce a common understanding of, and alignment around, the identity, goals, and values of the organization as defined by the organizers. Monica, a foodsharing ambassador and head of a regional foodsharing chapter, recalls the introduction of a quiz that should later become mandatory for every individual to be accepted as a member:

We have grown so fast and we also just have too many people that do not really share that idealism. But we want people to have a certain basic knowledge. Not only with regard to when foodsharing was created or what our goal is in foodsharing, but also how we deal with each other. It's really bad, but it's necessary. That's, that's the thing. . . . We said we must force people to deal with the topic, with the ideology, ... . the quiz is a reaction to all those conflicts, to all those issues we had. (Monica, ambassador, interview)

Through the introduction of a quiz, infornatin letters, and an internal wiki, the organizers normed and prescribed a joint identity, joint goal, and common values. Once those identity, values, and goals were codified in official texts, there was a clear expectation that new and existing members would engage with these texts in order to qualify as committed and hence "proper" members. 


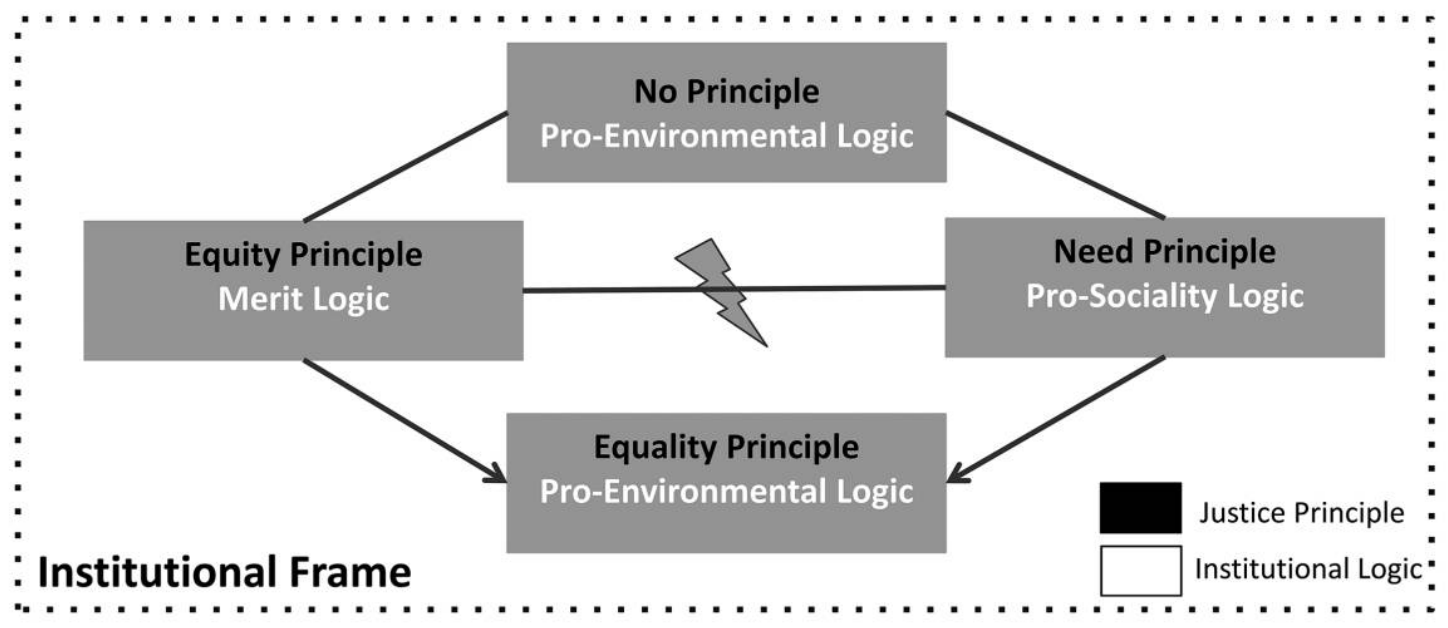

\begin{tabular}{|c|c|}
\hline $\begin{array}{c}\text { Pro-Environmental } \\
\text { Logic }\end{array}$ & $\begin{array}{l}\text { - Redistribution of food items that have been declared as } \\
\text { waste by the official market } \\
\text { - No distributive justice principle is explicitly implied }\end{array}$ \\
\hline Merit Logic & $\begin{array}{l}\text { - The more you contribute to foodsharing, the more you are } \\
\text { allowed to take away } \\
\text { - Equity Principle }\end{array}$ \\
\hline Pro-Sociality Logic & $\begin{array}{l}\text { - The collected food should be distributed to the poor } \\
\text { - Need-Principle }\end{array}$ \\
\hline Pro-Environmental & $\begin{array}{l}\text { - It is not about to whom the food is distributed, but about } \\
\text { the fact that it is redistributed } \\
\text { - Equality -Principle }\end{array}$ \\
\hline
\end{tabular}

Figure 1. Distributive justice and institutional logics.

But they [the organizers] are very strict. . . . The excuse that you have not been a member for long does not count, you need to gather information, you need to read, you need to be clear about how, well how [this works]. (Elisabeth, foodsaver, interview)

The organizers enforced a rigorous system of certification for foodsavers, that is, members who are exposed to external actors. So-called foodsaver IDs were only granted to individuals who had successfully passed the quiz and who had proven their serious commitment in the course of three trial pickups together with a senior member or ambassador. A monitoring system was included with these prescriptions to register (and ultimately sanction) breaches of the organizations' values (e.g., discarding saved food may lead to banning from the community).
Although the organizers engaged in various practices rooted in the proenvironmental logic to prescribe the common identity, goal, and values, they maintained or newly incorporated practices and structures that were embedded in the earlier conflicting logics of merit and prosociality. First, in order to attend to the logic of merit on the intraorganizational level, the organizers gradually built an organizational promotion system that offers members the possibility to show their performance record. For example, being nominated as an as ambassador certainly comes with benefits, such as status and some administrative power. However, members wishing to take on this role first have to earn their credits before climbing up the internal hierarchy. According to the latest wiki update (January 2015), members can only become an ambassador if they have successfully passed the quiz, have been registered as a food- 
saver for at least 6 months, have completed 15 food pickups within the last 6 months at registered partners, have no breaches registered, and have at least three "trust bananas" (trust bananas serve as a digital voucher accorded by other members trusting in an individual's integrity of conduct).

Second, the foodsharing organizers also incorporated practices from the logic of merit toward retailers in an attempt to obtain acceptance on the interorganizational level and thus in the broader institutional field. For example, the organizers have crafted behavioral guidelines for members on how to approach new retailers. In an 11-minute video tutorial, the organizers prescribe a detailed argumentation line toward retailers presenting the activities of foodsharing as a "service" to businesses and outlining the benefits that cooperating with foodsharing would have for them. In the video, one ambassador role-models her speech toward a fictional retailer:

Green consciousness and better sleep often do not count as an argument [right?]. But we can tighten it to money. You save on expenses for waste disposal, because we sort your waste and filter out what is still edible. We sort the waste! That means that your employees only put the waste somewhere and we do what your employees would usually have to do. What we can also offer you: a sticker which you can visibly display for your consumers to say that you don't waste food. (Monica, foodsharing ambassador in the video tutorial "Speaking with Businesses")

Through this video tutorial, the organizers want to make sure that members adapt their speech and demeanor to commercial actors embedded in the logic of merit. In order to be recognized by this target audience, the organizers draw from the equity-based principle by framing foodsaving as an "offer" to businesses and emphasizing its diverse monetary and nonmonetary benefits for them. As such, the foodsharing organizers prescribe a retailer-targeted image presenting foodsavers as committed volunteers (in contrast to scroungers) who provide time and effort in exchange for the "free" food that they ask of retailers.

Finally, to secure endorsement from actors championing the logic of prosociality, the foodsharing organizers decided to allow for the logic of prosociality to be incorporated in the organization to some degree. First, to attenuate the intraorganizational conflict that arose in spring 2014 around the question of whether saved food should be preferably given to the poor, the organizers allowed needy people to cover some of their subsistence needs through foodsharing by explicitly mentioning them as potential beneficiaries on the official website. Second, in spring 2015, the organizers incorporated the prosocial logic on a more structural level by opting into cooperation with Germany's biggest food bank, an organization traditionally embedded in the prosocial logic. In a press release in April 2015, foodsharing organizers explained this cooperation through the organizations' agreement on the joint goal of reducing food waste, though both organizations position themselves differently in the field: while food banks distribute surplus food exclusively to needy people, foodsharing circulates surplus food within a demographically more diverse but environmentally concerned public (including needy people). In this official statement about the newly created cooperation, the foodsharing organizers insisted that they would complement (rather than compete with) the food bank in a concerted effort to maximize the amount of saved food (e.g., in the form of intermediation by foodsharing between retailers and food banks if food amounts are too big to handle for foodsharing). We interpret the cooperation with an external actor epitomizing the logic of prosociality as a symbolic move by the foodsharing organizers on the interorganizational level to avoid conflict with a field incumbent who might consider the new entrant as a potential rival competing for the same resources.

In sum, through the endorsement of both the logic of merit and the logic of prosociality on the level of organizational structures, processes, and behaviors, foodsharing strategically signaled attendance to the demands posed by internal and external referents embedded in the diverging logics of merit and prosociality. Yet while doing so the organizers did not compromise on the dominance of the synthesizing logic, the proenvironmentalist logic, to which the other two logics were subordinate. Both the merit and prosociality logic were only incorporated to the extent that they would not compromise the dominant logic of proenvironmentalism and the related equality principle of redistribution. For example, the equity principle (embedded in the merit logic) was only built into the promotional system to reward ambassadors with status and administrative rights for their efforts. However, it did not extend into exclusivity for ambassadors regarding the appropriation of the saved food. Furthermore, the enactment of the merit logic in the cooperation with retailers was incorporated insofar as it helped to gain their support for food waste reduction but not to maximize foodsharing's supply of food. Similarly, the logic of prosociality was only included insofar as it did not alter 
foodsharing's positioning as an environmentally engaged organization. In their official statement about the newly created cooperation, the organizers insisted that their decision to cooperate with food banks was driven by their joint effort to maximize the amount of food saved from the bin but not to secure subsistence of needy individuals.

As such, the foodsharing organizers, in their role as institutional entrepreneurs, engaged in a mixed strategy to manage the conflict between logics. Foodsharing faced a situation where there was no accepted common goal from the outset. Therefore, the foodsharing organizers enforced a unified goal and joint identity, embedded in a superordinate logic, under which organizational elements embedded in other logics were incorporated to the degree that they would leave the dominant logic intact. Enforcing a dominant logic on the level of goals, identity, and values and simultaneously importing other organizational elements from other logics according to their compatibility with the enforced dominant logic is a strategy we call "hierarchical coupling." In the discussion section, we will outline how this strategy differs from hitherto identified strategies to manage conflicting logics (e.g., Pache and Santos 2013).

Figure 2 provides an overview of the milestones that have influenced foodsharing's evolvement over time and their arrangement according to the overall structure of our results. It shows how foodsharing organizers have both impacted and been impacted by the actions of other in- stitutional actors championing divergent institutional logics. Our study is thus in line with previous literature (e.g., Maguire and Hardy 2009; Purdy and Gray 2009) that holds that, especially in emerging fields, institutional entrepreneurs do not have unlimited agency but that their strategic work is dependent on and shaped by other internal and external actors and the context in which the institution is embedded.

\section{DISCUSSION}

Our research focuses on the conciliation of different distributive justice principles within the context of foodsharing. We show that the negotiation of principles of distributive justice follows the classical dialectical structure of thesis, antithesis, and synthesis (Marx 1956; Hegel 1977). Without prescribing any particular justice principle, foodsharing was soon the scene of a fairness dispute, in which the principle of equity (thesis) was pitted against the principle of need (antithesis). This conflict was resolved dialectically through the introduction of a third principle of justice (the principle of equality), which marked a synthesis beyond the two contending principles by shifting the discourse from an interpersonal-relational level to the level of a higher common objective. We found this discourse embedded in a process of institutional work in which different parties endorsed and enacted idiosyncratic principles of distributive
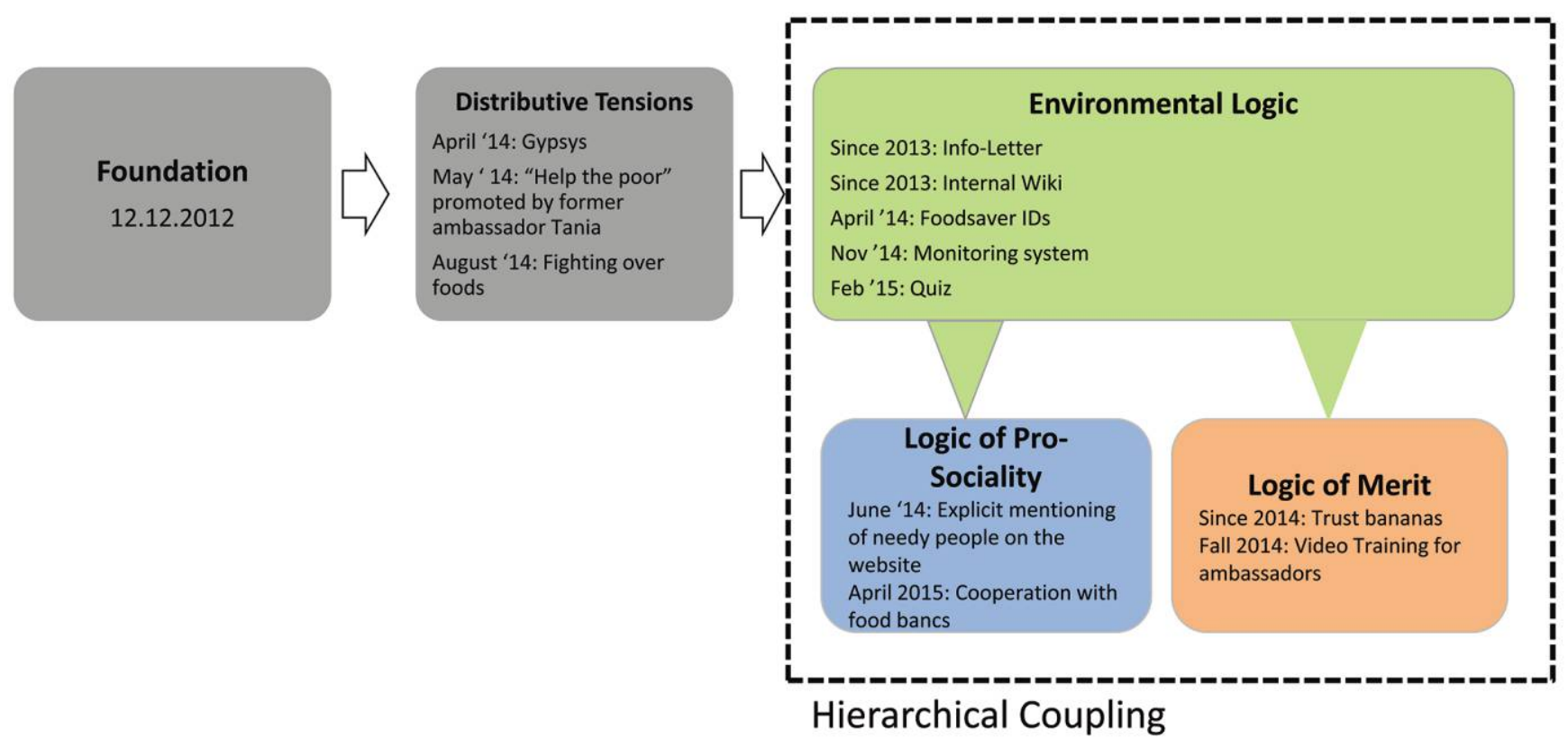

Figure 2. Unfolding of foodsharing. 
justice in order to advance a specific institutional logic. While the equity principle served to advance the logic of merit, the need principle served to advance the logic of prosociality. The equality principle finally served to advance the logic of proenvironmentalism. We now discuss theoretical implications of our work by relating it to prior work and theorizations.

\section{Fairness Accounts in Sharing}

Our analysis of foodsharing shows how one single sharing model can act as a nexus of different ideological orientations. As part of the emerging Sharing Economy in Germany, the studied organization is situated at the intersection of different logics that have developed as a matter of a specific cultural context. We found foodsharing caught between competing demands of the meritocratic, prosocial, and ecological logic prevailing in the studied context. These multiple logics percolating from the broader cultural context engendered multiple conceptions and contradicting practices of "fair sharing" by different organizational actors. As such, the present conceptions of fairness are influenced not only by the immediate organizational context and the processes of institutional work (that will be discussed in the next section) but also by the larger cultural context (Askegaard and Linnet 2011). In our case, this broader cultural context shaped organizational actions through an extensive public discourse on what sharing is and what it is not in the light of ideologies associated with sharing and related principles of justice. We therefore suggest that considerations of more macro-level factors are needed for understanding how fairness is constructed within nonmonetary sharing systems as a particular mode of resource circulation. This is in line with earlier voices that criticized the conceptualization of sharing in consumer research as a conceptual universalism (Siebert 2013; Arnould and Rose 2015). Our analysis of how divergent constructions of fairness can emerge within a concrete nonmonetary sharing system can contribute to understanding struggles in cognate sharing systems in which the absence of explicit reciprocal rules leaves the circulation of resources a nebulous activity. Unclear situations of fairness similar to the present context can, for example, be found in other nonmonetary models of the Sharing Economy, such as booksharing (Corciolani and Dalli 2014), the peer-to-peer hospitality platform CouchSurfing (Bialski 2012; Hellwig et al. 2014), or Skoros, a "for-free-shop" in Greece (Skoros 2015). For example, Skoros encountered similar struggles within its community regarding distributive norms and underlying justice principles. During the recent economic crisis, the organization's initial distributive principle of "sharing among equals" (i.e., equality principle) was contested by influences percolating from the broader context, leading to an increasing emphasis on "helping the poor" put forth by some actors stressing a distributive principle of need. This example corroborates our insight from the German foodsharing context in the sense that macro factors prevailing in the respective cultural sphere need to be taken into account in order to understand how fairness is constructed in different nonmonetary sharing systems.

\section{Managing Conflicting Logics in Emerging Sharing Models} In the present case, the conflict between competing justice principles that were enacted by different groups of actors helped the organization's leaders to reflect on "their" institutional logic that they had not yet anchored in a straightforward justice principle. The tensions that arose between the "need principle" and the "equity principle" as manifestations of two conflicting institutional logics epitomized a crucial intermediate step for the organization, making the organizers realize what fairness in foodsharing shall not be. Or, respectively, which kinds of fairness are not compatible with their own vision. Realizing, understanding, and resolving existing tensions thus helped the organization to plead in favor of its initial objective and the according justice principle of equality that was subsequently used as a synthesizing superordinate logic to align the conflicting antitheses. In particular, the subsequent work that has been done to obtain acceptance for the dominance of the superordinate logic of proenvironmentalism was crucial for the organizers to contain the actions of their various actors coming from diverging ideological camps. In their function as institutional entrepreneurs, the organizers engaged in a mixed strategy of managing conflicting logics that we qualify as "hierarchical coupling." We propose this strategy as an extension to the existing strategies that have been identified in institutional theory literature as "decoupling," "compromising," and "selective coupling" (Pache and Santos 2013). Our notion of "hierarchical coupling" comes closest to a mix between (i) "selective coupling" and (ii) compromising. This is because it (i) eclectically combines organizational elements from two divergent logics and it (ii) combines these diverging elements only to a reduced degree. However, this mix is enacted under the dominance of a third, synthesizing logic (in this case the proenvironmentalist logic). The hierarchical aspect is what differentiates "hierarchical coupling" from "selective coupling" and "compromising," 
as none of them specifies the a priori dominance of a higher logic under which the competing logics are subsumed. This finding contributes to the literature on managing conflicting logics in general and in particular to the emerging literature in consumer research on the Sharing Economy.

Given the competing logics we found in the context of foodsharing, we believe that such pluralism of logics permeates the broader "Sharing Economy," where monetary and nonmonetary sharing systems struggle for acceptance in a field occupied by commercial businesses, nonprofit organizations, and state regulators. An organization's ability to manage diverging logics both internally and externally will be of utmost importance to secure support and resources in the future. Given the short existence of the foodsharing organization, we are not able to conclude whether hierarchical coupling is an efficient, or even superior, strategy in the long term. Whether, and in which configuration, organizations should alternate between strategies to manage conflicting logics is certainly an interesting question for further research.

\section{Goal-Sharing}

Our analysis shows how recentering the focus on the initial proenvironmental logic of foodsharing and its concrete goal, namely, to save food from being thrown away uneaten, helps the organization to transcend the contest between opposing institutional logics that lead to conflicting ideas of redistributive justice at first place. This finding points at the close relationship between institutional logics and concrete norms of fairness, especially in contexts in which solid reciprocities as anchor points for equity-based justice accounts are hidden or absent.

We found foodsharing organizers to center the organizational focus on the circulated object rather than on individual actors or their relationship. This finding extends the sociopsychological literature that predominantly looks at principles of justice from a relational perspective (Fiske 1991; Tetlock 2003; McGraw and Tetlock 2005; Fiske 2012). In the present context, the organizers succeeded in reconciling distributive conflicts between different member camps by valuing the object (i.e., the food that is to be distributed) higher than the subject (i.e., individual interests in receiving the food) in considerations of distributive justice. As a consequence, the relationships between individuals within the community were shifted to the periphery of the question of fair distribution.

Such a perspective is also in stark contrast to most of the existing work on nonmonetary marketplaces where the ex- change of goods and services reinforce communal bonds, be it on a dyadic (Sherry 1983; Belk and Coon 1993), a systemic (Giesler 2006), or an intracommunal (Weinberger and Wallendorf 2012) level. This is due to the special position of the object within the foodsharing community. None of the active members is a donor of the shared objects but all are potential recipients. The actual donors, namely the retailers, are not active members of the community and therefore only play an implicit role for negotiations of justice. Among the foodsharing members, there are therefore no intracommunal reciprocal expectations or moral obligations similar to Giesler's (2006) gift-giving system of file sharing. Moreover, we could not identify particular flows of gratitude among members, as, for example, found in Weinberger and Wallendorf's (2012) investigation of giftgiving at the Mardi Gras parades in New Orleans. Whenever gratitude or obligation was expressed, this took the form of thankfulness and respect toward natural resources and human and animal producers of the food objects.

Especially the absence of reciprocal claims in Belk's (2010) definition of sharing has been widely criticized within consumer research (Corciolani and Dalli 2014; Arnould and Rose 2015). Our findings show, however, that whenever a superordinate goal that is in no direct connection with the interpersonal relationships of the marketplace actors guides the redistribution of a resource, reciprocities between subjects become unnecessary for keeping the social interaction going. This is in line with recent research on communities of purpose as "social interaction system [s] organized among people with shared or overlapping goals in order to pursue privileged outcomes" (Schouten and Martin 2011). Therefore, we suggest that whenever the circulation of resources is aimed at contributing to a higher common goal that goes beyond individual needs and goals, and especially beyond reciprocal claims, "sharing" as a form of redistribution can take place. This means that a common grander goal elevates the mutual objective beyond the interests of individual actors and allows for redistribution within the group in detachment from reciprocity principles. Such detachment from reciprocity is what differentiates the present case from commodity exchange or gift-giving. However, what is observed here also contrasts with Belk's (2010) definition of sharing, in which the facilitation of human connectedness is the second central defining principle of sharing. Rather, compared to the higher goal of the group, we find interpersonal connection to play a subordinate role in the redistributive processes of foodsharing. 
In line with Schouten and Martin's (2011) research on communities of purpose, we suggest designating what is observed here as "goal-sharing," where a unifying belief in a superordinate goal beyond the personal and interpersonal level allows for a nonreciprocal redistribution of resources that relies on an equality principle of justice. In contrast, the primary objective of gift-exchanges, but also of "sharing-in" as defined by Belk (2010), is to initiate and maintain interpersonal relationships, and it thus centers on the relationship dyad or the community. However, nonreciprocal "goal-sharing" requires subjective but also relational goals to fade out so as to create an entity in which attention is focused on a grander goal.

\section{LIMITATIONS AND FURTHER RESEARCH}

Certainly our study is not without limitations. Although we attempted to address a sample that does justice to the range of users participating in foodsharing, we acknowledge that our results might not be generalizable without confines. We are well aware that our study is situated within the context of Germany, a Western industrialized nation facing food affluence (Evans, Campbell, and Murcott 2012). It is probable that a system like foodsharing would not be easily transferrable to the context of a less developed country facing food scarcity. Accordingly, we acknowledge that our findings are to be understood within the limits of a Western conception of sharing, justice principles, and customs of food consumption.

Our study can be seen as a first attempt to integrate considerations of fairness into research on sharing systems. However, a full understanding of the role of fairness in sharing will require further studies that pay justice to the diversity of sharing systems. For instance, the role of freeriding could be an interesting avenue for further research, especially with regard to the amount of freeriding that such systems can bear before falling apart.

Furthermore, foodsharing, as a form of public sharing where the available resources are not shared within donorrecipient dyads (i.e., retailers and individuals) but is redistributed by the foodsharing organization like in a hub system, points to the question of legal and psychological ownership (Jussila et al. 2015). Including ownership accounts within the investigation of fairness in sharing systems might offer a fruitful further research avenue.

Future research, together with our present study, can help academics and practitioners understand the tensions and dynamics that are to be handled by managers of nonmonetary sharing systems if they want to move their emerg- ing organization out of an alternative niche state and gain acceptance from a broad audience to ensure its future stability and sustainable growth.

\section{REFERENCES}

Akerlof, Georg A., and Robert J. Shiller (2010), Animal Spirits: How Human Psychology Drives the Economy, and Why It Matters for Global Capitalism, Princeton, NJ: Princeton University Press.

Alford, Robert, and Roger Friedland (1985), Powers of Theorv: Capitalism, the State, and Democracy, Cambridge: Cambridge University Press.

Andrade, Nazereno, Fransciso Brasileiro, Walfredo Cirne, and Miranda Mowbray (2004), "Discouraging Free Riding in a Peer-to-Peer CpuSharing Grid," in Proceedings of the Thirteenth IEEE International on Symposium on High Performance in Distributed Computing, Piscataway, NJ: IEEE, 129-37.

Andreoni, James (1989), “Giving with Impure Altruism: Applications to Charity and Ricardian Equivalence," Journal of Political Economy, 97 (6), 1447-58.

Arnould, Eric J., and Alexander S. Rose (2015), "Mutuality Critique and Substitute for Belk's 'Sharing,'” Marketing Theory, March 2, 1-15.

Askegaard, Søren, and J. T. Linnet (2011), “Towards an Epistemology of Consumer Culture Theory: Phenomenology and the Context of Context," Marketing Theory, 11 (4), 381-404.

Bardhi, Fleura, and Giana M. Eckhardt (2015), “The Sharing Economy Isn't about Sharing at All," Harvard Business Review, 39 (4), 881-98.

Bartlett, Christopher, and Sumantra Collins (2011), Aristotle's Nicomachean Ethics, Chicago: University of Chicago Press.

Batson, Charles Daniel (1991), The Altruism Question: Toward a SocialPsychological Answer, Hillsdale, NJ: Lawrence Erlbaum Associates.

Belk, Russell W. (2007), "Why Not Share Rather than Own?" ANNALS of the American Academv of Political and Social Science, 611 (1), 126-40. - (2010), "Sharing," Journal of Consumer Research, 36 (5), 715-34. - (2013), "Sharing versus Pseudo-Sharing in Web 2.0," Anthropologist, 4 (2), 7-23.

Belk, Russell W., and Gregory S. Coon (1993), “Gift Giving as Agapic Love: An Alternative to the Exchange Paradigm Based on Dating Experiences," Journal of Consumer Research, 20 (3), 393-417.

Benkler, Yochai (2004), "Sharing Nicely: On Shareable Goods and the Emergence of Sharing as a Modality of Economic Production," $\underline{\text { Yale }}$ Law Journal, 114 (2), 273-358.

Bialski, Paula (2012), "Technologies of Hospitality: How Planned Encounters Develop between Strangers," Hospitality and Society, 1 (3), 245-60.

Bos, Kees Van den, and Joost Miedema (2000), “Toward Understanding Why Fairness Matters: The Influence of Mortality Salience on Reactions to Procedural Fairness.," Journal of Personality and Social Psychology, 79 (3), 355-61.

Botsman, Rachel, and Roo Rogers (2011), What's Mine Is Yours: How Collaborative Consumption Is Changing the Way We Live, London: Collins.

Cagle, Susie (2014), "The Case against Sharing: On Access, Scarcity, and Trust," The Nib, May 27, https://thenib.com/the-case-against-sharing -9ea5ba3d216d.

Corciolani, Matteo, and Daniele Dalli (2014), "Gift-Giving, Sharing and Commodity Exchange at Bookcrossing.com: New Insights from a Qualitative Analysis," Management Decision, 52 (4), 755-76.

“Couchsurfing Statistics 2015" (2015), Infogr.am, https://infogr.am /couchsurfing-statistics. 
Crilly, Donal, Maurizio Zollo, and Morten T. Hansen (2012), "Faking It or Muddling Through? Understanding Decoupling in Response to Stakeholder Pressures," Academy of Management Journal, 55 (6), 1429-48.

Deutsch, Morton (1975), "Equity, Equality, and Need: What Determines Which Value Will Be Used as the Basis of Distributive Justice?" Journal of Social Issues, 31 (3), 137-49.

DiMaggio, Paul J., and Walter W. Powell (2012), The New Institutionalism in Organizational Analysis, Chicago: University of Chicago Press.

Dolbec, Pierre-Yann, and Eileen Fischer (2015), "Refashioning a Field? Connected Consumers and Institutional Dynamics in Markets," Journal of Consumer Research, 41 (6), 1447-68.

Douglas, Mary (1990), "Foreword," in The Gift: The Form and Reason for Exchange in Archaic Societies, ed. Mary Douglas, London: Routledge, 9-23.

Esping-Andersen, Gosta (1989), "The Three Political Economies of the Welfare State," Canadian Review of Sociologv/Revue Canadienen de Sociologie, 26 (1), 10-36.

Evans, David, Hugh Campbell, and Anne Murcott (2012), "A Brief Prehistory of Food Waste and the Social Sciences," Sociological Review, 60 (December), 5-26.

Feather, Norman T. (1994), "Human Values and Their Relation to Justice," Journal of Social Issues, 50 (4), 129-51.

Fehr, Ernst, Helen Bernhard, and Bettina Rockenbach (2008), "Egalitarianism in Young Children," Nature, 454 (7208), 1079-83.

Fiske, Alan P. (2012), "The Four Elementary Forms of Sociality: Framework for a Unified Theory of Social Relations," Psychological Review, 99 (4), 689-723.

"Foodsharing" (2015), http://wiki.lebensmittelretten.de/Kontext_und Selbstverst\%C3\%A4ndnis.

Forsyth, Donelson (2006), Group Dynamics, 4th ed., Belmont, CA: Thompson Higher Education.

Gansky, Lisa (2010), The Mesh: Why the Future of Business Is Sharing, New York: Portfolio.

Giesler, Markus (2006), “Consumer Gift Systems," Journal of Consumer Research, 33 (2), 283-90.

Greenwood, Royston, Mila Raynard, Farah Kodeih, Evelyn Micelotta, and Michael Lounsbury (2011), "Institutional Complexity and Organizational Responses," Academv of Management Annals, 5 (1), 317-71.

Hegel, Geory W. F. (1807/1977), Phenomenology of Spirit. 1807, Oxford: Oxford University Press.

Hellwig, Katharina, Felicitas Morhart, Bruno Kocher, and George Zisiadis (2014), "Share Your Life and Get More of Yourself: Experience Sharing in CouchSurfing," in NA Advances in Consumer Research, ed. June Cotte and Stacy Wood, Duluth, MN: Association for Consumer Research, 510-11.

Humphreys, Ashlee (2010a), "Megamarketing: The Creation of Markets as a Social Process," Journal of Marketing, 74 (2), 1-19.

(2010b), "Semiotic Structure and the Legitimation of Consumption Practices: The Case of Casino Gambling," Journal of Consumer Research, 37 (3), 490-510.

Jussila, Iiro, Anssi Tarkiainen, Marko Sarstedt, and Joseph F. Hair (2015), "From the Special Issue Guest Editors," Journal of Marketing Theory and Practice, 23 (2), 119-20.

Kraatz, Matthew S., and Emily S. Block (2008), "Organizational Implications of Institutional Pluralism," in The Sage Handbook of Organizational Institutionalism, ed. Royston Greenwood, Christine Oliver, Roy Suddaby, and Kerstin Sahlin-Andersson, Thousand Oaks, CA: Sage, 243-75.

Lamberton, Cait P., and Randall L. Rose (2012), "When Is Ours Better than Mine? A Framework for Understanding and Altering Partici- pation in Commercial Sharing Systems," Journal of Marketing, 76 (4), 109-25.

Lawrence, Thomas B., and Roy Suddaby (2006), "Institutions and Institutional Work," in Sage Handbook of Organization Studies, ed. Stewart R. Clegg, Cynthia Hardy, Thomas B. Lawrence, and Walter R. Nord, London: Sage, 215-54.

“Leaders' Declaration G7 Summit 2015" (2015), The White House: Office of the Press Secretary, https://www.whitehouse.gov/the-press-office /2015/06/08/g-7-leaders-declaration.

Maguire, Steve, and Cynthia Hardy (2009), "Discourse and Deinstitutionalization: The Case of DDT," Academv of Management Journal, 52 (1), 148-78.

Marx, Karl (1956), The Poverty of Philosophy, New York: Cosimo, Inc.

McArthur, Ellen (2014), "Many-to-Many Exchange without Money: Why People Share Their Resources," Consumption Markets and Culture, 18 (3), 1-18.

McCracken, Grant (1988), The Long Interview, London: Sage.

McGraw, A. Peter, and Philip Tetlock (2005), "Taboo Trade-Offs, Relational Framing, and the Acceptability of Exchanges," Journal of Consumer PSVchology, 15 (1), 2-15.

Meyer, John W., and Brian Rowan (1977), "Institutionalized Organizations: Formal Structure as Myth and Ceremony," American Journal of Sociologv, 83 (2), 340-63.

Ozanne, Lucie K., and Paul W. Ballantine (2010), "Sharing as a Form of Anti-consumption? An Examination of Toy Library Users," Journal of Consumer Behaviour, 9 (6), 485-98.

Pache, Anne Claire, and Filipe Santos (2013), "Inside the Hybrid Organization: Selective Coupling as a Response to Competing Institutional Logics," Academy of Management Journal, 56 (4), 972-1001.

Purdy, Jill M., and Barbara Gray (2009), "Conflicting Logics, Mechanisms of Diffusion, and Multilevel Dynamics in Emerging Institutional Fields," Academv of Management Journal, 52 (2), 355-80.

Sachs, Jeffrey (2006), The End of Poverty: Economic Possibilities for Our Time, London: Penguin.

Sacks, Danielle (2011), "The Sharing Economy," Fast Company Magazine, April 18.

Sandel, Michael J. (2010), Justice: What's the Right Thing to Do? London: Macmillan.

Scaraboto, Daiane (2015), "Selling, Sharing, and Everything in Between: The Hybrid Economies of Collaborative Networks," Journal of Consumer Research, 42 (1), 152-76.

Scaraboto, Daiane, and Eileen Fischer (2013), "Frustrated Fatshionistas: An Institutional Theory Perspective on Consumer Quests for Greater Choice in Mainstream Markets," Journal of Consumer Research, 39 (6), 1234-57

Schouten, John W., and Diane M. Martin (2011), "Communities of Purpose," in Changing Consumer Roles: An Anthology, ed. Karin M. Ekström and Kay Glans, London: Routledge, 125-36.

Scott, Richards W. (2008), Institutions and Organizations: Ideas and Interests, Thousand Oaks, CA: Sage.

Sherry, John F. (1983), “Gift Giving in Anthropological Perspective,” Journal of Consumer Research, 10 (2), 157-68.

Siebert, Anton (2013), "How Non-Western Consumers Negotiate Competing Ideologies of Sharing through the Consumption of Digital Technology," in The Routledge Companion to Digital Consumption, ed. Russell W. Belk and Rosa Llamas, New York: Routledge, 137-47.

Skoros (2015), Skoros: Anti-consumption in Crisis, Greece, https://www youtube.com/watch?v $=$ z8fAmi0mHgA.

Slater, Don (2000), Consumption without Scarcity: Exchange and Normativity in an Internet Setting, Oxford: Berg. 
Tetlock, Philip E. (2003), "Thinking the Unthinkable: Sacred Values and Taboo Cognitions," Trends in Cognitive Sciences, 7 (7), 320-24.

Thompson, Craig J. (1997), "Interpreting Consumers: A Hermeneutical Framework for Deriving Marketing Insights from the Texts of Consumers' Consumption Stories," Journal of Marketing Research, 34 (November), 438-55.
Triandis, Harry C. (1994), Culture and Social Behavior, New York: Mcgraw-Hill. Weinberger, Michelle F., and Melanie Wallendorf (2012), "Intracommunity Gifting at the Intersection of Contemporary Moral and Market Economies," Journal of Consumer Research, 39 (1), 74-92.

Wilk, Richard (2001), "Consuming Morality," Journal of Consumer Culture, 1 (2), 245-60. 